\title{
The effects of dispersal and recruitment limitation on community structure of odonates in artificial ponds
}

\author{
Shannon J. McCauley
}

\begin{abstract}
I examined the effects of isolation on the structure of both adult and larval dragonfly (Odonata: Anisoptera) communities forming at physically identical artificial ponds over two years. Isolation, whether measured by distance to the nearest source habitat or by connectivity to multiple sources, was significantly negatively related to the species richness of dragonflies observed at and collected in these ponds. These results indicate that dispersal and recruitment limitation acted as filters on the richness of communities at these artificial ponds. The richness of larval recruits in artificial ponds was lower than the richness of adult dispersers observed at ponds, and distance from a source habitat explained a greater fraction of the variation in larval than adult richness ( 83 and $50 \%$, respectively). These results and a male biased sex-ratio in adults observed at artificial ponds suggest that isolated habitats may be more recruitment limited than observations of dispersers would suggest. A Mantel test indicated there was a spatial component to the composition of communities forming in tanks, and that distance between tanks and community dissimilarity (1-Jaccard's) were significantly positively related $(\mathrm{r}=0.52)$. This pattern suggests that their position with respect to alternative source environments influenced the composition of the communities that recruited into these ponds. These results provide further evidence of recruitment limitation in this system. Results from this study highlight the importance behaviorally limited dispersal may have in taxa morphologically capable of broad dispersal and suggest that the role of dispersal and recruitment limitation may be critical in shaping community structure across habitat gradients that include variation in habitat duration.
\end{abstract}

S. J. Mc Cauley

Dept of Ecology and Evolutionary Biology, Univ. of Michigan, Ann Arbor, MI 48109-1048, USA

Factors that affect community structure are often divided into two general categories, local (nicheassembly) processes and regional (dispersal-assembly) processes (Ricklefs 1987). Both sets of processes can act as filters on the composition of local communities (Poff 1997). Local processes, including species interactions and abiotic tolerances, can determine whether species are able to establish and maintain populations once they have reached a habitat. Regional factors, including the size of the species pool as well as dispersal and recruitment, may also affect species composition within local sites, by placing an upper boundary on species richness and by limiting the numbers of species arriving at sites suitable for local establishment (MacArthur and Wilson 1967, Cornell and Lawton 1992, Srivastava 1999). Understanding the extent to which communities may be structured by processes at either level is a critical question in ecology and is central to the field of metacommunity ecology (Leibold et al. 2004). 
Despite the growth of a metacommunity perspective in ecology, there is still a general paucity of information on dispersal rates and distances for most species and a lack of explicit tests of the effects of habitat isolation and connectivity on community structure. The lack of data on dispersal limitation and the spatial arrangement of habitats on community structure constrains our ability to interpret the importance of regional processes for many systems. This gap is striking in lentic freshwater systems. In these systems, the effects of local processes including habitat permanence and species interactions have been extensively examined and can clearly impact community structure (Schneider and Frost 1996, Wellborn et al. 1996, Urban 2004). However, the intrinsically patchy structure of these habitats, as well as a continuum of local extinction rates related to habitat permanence, suggests that dispersal limitation is also likely to impact the richness and composition of many ponds. The roles of dispersal and recruitment limitation have been less extensively explored than the role of local processes in structuring freshwater aquatic systems, particularly for invertebrate groups other than zooplankton (Wilcox 2001).

An experimental approach was used to assess the potential effects of dispersal and recruitment limitation on the community structure of dragonflies (Odonata: Anisoptera) in temperate freshwater pond communities. This study presents results from a portion of this work on the effects of these processes on community patterns including species richness and spatial effects on community composition. Dragonflies have several characteristics that make them a useful system in which to address these questions. First, surveys of dragonfly communities in natural water-bodies find a positive relationship between species richness and habitat duration (McCauley 2005). Most of these species require water throughout their larval development but many species are found in sink habitats where they can never complete development and in periodic sink habitats that hold water long enough for development during some, but not all, periods (McCauley 2005). Therefore, richness and composition in non-permanent ponds will be affected by the recolonization rate of these species. This group is also highly diverse. Forty-five species were collected from 57 lakes and ponds in the region where this study was conducted (McCauley 2005). Finally, the high potential vagility of these species makes this a conservative system in which to look for dispersal limitation.

Evidence of dispersal limitation in dragonflies would suggest that this process may have further implications for community structure, indicating the importance of behavior in generating dispersal limitation over physiological or morphological capacities. It also provides an important contrast to zooplankton communities where more extensive work on dispersal limitation has been conducted (Shurin 2000, Cáceres and Soluk 2002, Cottenie and De Meester 2003, 2004, Cotennie et al.
2003). Unlike many zooplankton, dragonflies and many other aquatic taxa are active dispersers and are incapable of asexual reproduction (the single exception to this in odonates is an isolated population of Ischnura hastata in the Azores, Cordero Rivera et al. 2005). These characteristics will strongly influence the role dispersal and recruitment limitation play in determining community structure. Active dispersal may be expected to decrease the effect of these processes, but also results in individuals having significant behavioral control over dispersal. Obligate sexual reproduction results in both the size and sex ratio of the dispersal kernel being important components determining the probability of recruitment.

This experiment tested the effects of dispersal and recruitment limitation by following the formation of dragonfly communities at small artificial ponds. Three central questions were addressed in this experiment: 1) what is the relationship between habitat isolation and species richness? 2) If isolation affects richness at artificial ponds, is the magnitude of the impact the same for adult dispersers and larval colonists? If not, what mechanisms might produce this pattern? 3) Is there a spatial pattern to the community composition at artificial ponds spread across a landscape which has sources that vary in their composition? If dispersal and recruitment limitation do not affect community structure, no relationship would be expected between richness and the isolation of these physically identical ponds from source habitats, nor would we expect a relationship between their placement in the landscape and the composition of communities forming within them.

\section{Materials and methods}

Artificial ponds (cattle tanks) were established in May 2002 and monitored through October 2003 for dragonflies dispersing to and colonizing ponds. Sites were located on the Edwin S. George Reserve (hereafter: ESGR) and the neighboring Fresh Air Camp in southeast Michigan $\left(42^{\circ} 28^{\prime} \mathrm{N}, 84^{\circ} 00^{\prime} \mathrm{W}\right.$; Fig. 1). Cattle watering tanks ( $1.9 \mathrm{~m}$ in diameter and ca $0.5 \mathrm{~m}$ deep) were filled with 1300 liters of well water, and initial conditions were created that could support larval dragonflies (Table 1). Water was added to tanks when necessary to maintain them near to the starting volume. Lack of emergent vegetation in artificial ponds limited the recruitment of endophytic species. Consequently, species in the families Libellulidae and Corduliidae dominated both adult visitation and larval colonization of these artificial ponds and these results should be interpreted for these groups. These two families, however, represent the majority of species $(71 \%)$ in the surrounding pond communities (McCauley 2005). Water and other materials (e.g. leaves, zooplankton) used in all tanks were from the same source for each component. These materials 


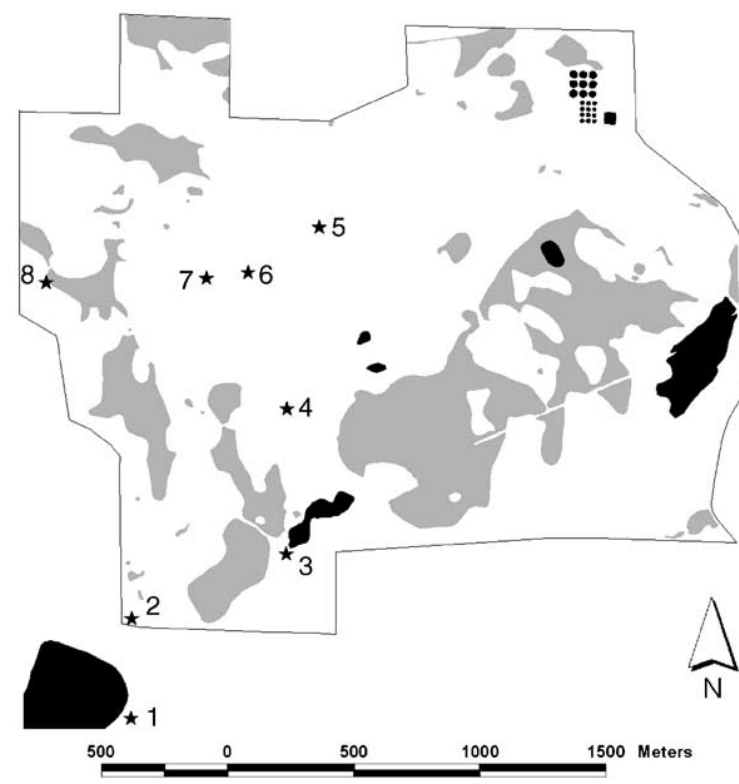

Fig. 1. Map of study sites (Edwin S. George Reserve inside outline). Stars indicate the midpoint between a pair of cattle tanks established in 2002 as artificial ponds. Tanks are labeled with a number and species observed at or collected in each set of tanks are given in Appendices A and B. Non-permanent wetlands are indicated in grey while permanent source ponds are indicated in black. The set of experimental ponds in the northeast corner of the map were treated as a single pond by summing their area in connectivity measures. One source used in connectivity measures is located off the map, approximately one kilometer south of the ESGR.

were collected so as to minimize the possibility of contamination by aquatic sources (e.g. leaves were collected far from any ponds, zooplankton were from a previously established culture, and water was drawn from an underground well). Tanks were arranged in sites across a landscape in which the drying histories of waterbodies had been followed for six years and the larval dragonfly community had been sampled for 2-6 yr prior to the beginning of this study (details of surveys by Werner et al. pers. comm., details of results involving larval dragonflies are covered in McCauley 2005 and in McCauley et al. unpubl.). Water-bodies in this landscape include a broad range of permanence levels including ponds that dry every year, ponds that dry periodically (e.g. with average drying intervals of between 2 and $30 \mathrm{yr}$ ), and permanent lakes that are likely to have not dried in hundreds of years.

Pairs of tanks were initially established as replicates. Because of concerns over the independence of adults observed at replicate tanks, results from each pair were combined and analyzed as a unit. Although this may reduce the power of analyses, cutting the potential sample size in half, it provides a more conservative measure of dispersal and colonization limitation. A total of eight pairs of tanks were set up at sites where there was minimal tree canopy cover. The degree of pond shading and the amount of polarized light reflected from ponds can affect site detection by dragonflies (Bernath et al. 2002) and a survey of dragonfly larvae in natural ponds in this area found a strong negative relationship between pond canopy cover and larval richness and abundance (McCauley et al. unpubl.). Therefore, tanks were located in the open field environments available on the ESGR. These conditions are most similar to the vegetation structure of permanent lakes as pond permanence and canopy cover are typically negatively related (Werner and Glennemeier 1999, McCauley et al. unpubl.). Using open canopy areas adjacent to potential sources and in old fields and using identical artificial pond habitats minimized

Table 1. Initial conditions present in cattle tanks and sampling dates for adults and larvae.

2002

2003

Elements adding

structural

complexity in each tank

Resources

Adult sampling dates

Larval sampling dates
4 dowels clipped to tanks as perches;

2 floating rope bundles

(each ca $60 \mathrm{~cm}$ of rope) and 2 rope bundles

(each ca $140 \mathrm{~cm}$ ) weighted to bottom with a

brick to simulate macrophytes;

$300 \mathrm{~g}$ of oak leaves;

Window screening suspended in tanks to provide complexity and substrate for larvae to move through tank.

$300 \mathrm{~g}$ of oak leaves;

$60 \mathrm{ml}$ rabbit chow;

20 Daphnia.

Period 1: 24-26 June

Period 2: 8-11 July

Period 3: 22-26 July

Period 4: 8-9 August

Sample 1: 9-12 July

Sample 2: 23-29 August

Sample 3: 4-11 October
Large stick (ca $150 \mathrm{~cm}$ ) as a perch;

2 floating rope bundles

(each ca $60 \mathrm{~cm}$ of rope) and 2 rope bundles

(each ca $140 \mathrm{~cm}$ ) weighted to bottom with a

brick to simulate macrophytes;

remains from $300 \mathrm{~g}$ of oak leaves added in 2002

plus natural leaf inputs;

window screening suspended in tanks

to provide complexity and substrate

for larvae to move through tank.

No new resources added;

well-developed zooplankton

populations in tanks.

Period 1: 20-23 June

Period 2: 2-3 July

Period 3: 21-24 July

Period 4: 4-5 August

Period 5: 18-19 August

Sample 1: 30 April-2 May

Sample 2: $11-15$ August

Sample 3: 6-10 October 
environment by distance covariance and mimicked the conditions utilized by the majority of species in this system. A pair of tanks were placed directly adjacent to each of three water-bodies that represent different points along the permanence-predator gradient common in southeast Michigan: a permanent lake with largebodied fish as top predators, a permanent lake with small-bodied fish as top predators, and a semipermanent pond (which dried in 2001 and 2002) with invertebrates as top predators. Five tank pairs were then placed in available fields on the ESGR at varying distances from the three ponds and other aquatic habitats that served as potential sources for dragonflies dispersing to and colonizing tanks (Fig. 1).

The results presented here are part of a broader study investigating the movement of dragonflies away from their different source environments, and sites were selected to form transects outward from the three habitats with tanks placed directly adjacent. This study, however, focused on the effects of connectivity to a larger set of permanent water-bodies on the community of dispersers and colonists arriving at artificial ponds rather than distances from a single source. Permanent water-bodies (defined as one that had not dried during a three year period prior to beginning of this experiment or during this experiment) were the only source environment for the vast majority of species in this system. Only one species collected as a larval colonist in this experiment has a desiccation-resistant egg stage and regularly survives pond drying in this stage (Boehms 1971). This species (Sympetrum vicinum) is, however, most abundant in permanent habitats. In a survey of 25 lakes and ponds, this species was found in 3 out of 8 (38\%) nonpermanent ponds and in 16 out of $17(94 \%)$ permanent lakes at an average of $30 \%$ higher densities in the permanent lakes relative to the non-permanent lakes (McCauley unpubl.). Given occupancy rates, densities, and that the average area of permanent lakes (and so total population size) is much greater than nonpermanent lakes, the majority of $S$. vicinum individuals in this region are therefore derived from permanent habitats. Therefore, non-permanent wetlands were not potential sources for the majority of the species pool considered here and were not used in measures of connectivity. Site selection for artificial ponds was constrained based on locating appropriate open-field terrestrial environments at a range of distances from water-bodies. The resulting arrangement of tanks therefore represents the best possible design given the structure of this landscape and the desire to have tanks at a range of distances away from the full range of habitat types in this region. This design represents a trade-off between control and realism, and a more controlled set of distances to a single focal site could only have been achieved by conducting this experiment at a smaller spatial scale considered unrealistic for the system. Given the density of water-bodies in the study region (a terminal moraine region of a previously glaciated land area) placing artificial ponds at a range of distances from a single focal lake and eliminating the role of dispersal from other water-bodies would require placing them at distances ca $250 \mathrm{~m}$ and less or utilizing greater range of terrestrial sites (i.e. both forested and field sites). This would be unlikely to capture realistic movement scales of adult dragonflies and would introduce new variables (e.g. level of canopy cover over tanks) into the study. Placing artificial ponds in terrestrial habitats which were all surrounded by similar vegetation (low growing grasses and forbs) and were all in open canopy sites eliminated the environment-distance covariance issue that makes it difficult to interpret spatial patterning in communities within natural habitats. Therefore, these results provide a means of examining how species differ in their propensity to visit and colonize new habitats at a realistic landscape scale while using identical habitats to control for the effects of habitat size and other habitat characteristics. This method represents a novel approach to studying dispersal and recruitment in aquatic organisms.

To measure dispersal to tanks, observations of adult dragonflies were conducted in both years. Passive observation rather than capture was used because capturing and handling adult dragonflies may increase their probability of moving away from the site of capture (Koenig and Albano 1987). Four sets of observations were made in 2002 and five in 2003. Observations were spread throughout the adult flying season (Table 1). Observations were conducted by sitting $1-2 \mathrm{~m}$ away from an individual tank and periodically scanning for adult dragonflies at the tank and surrounding area using binoculars. The observer scanned a minimum of 4 times $\min ^{-1}$ and watched the tank directly between scans. Each observation period lasted $10 \mathrm{~min}$, for a total of $180 \mathrm{~min}$ per pair of tanks. The length of observation periods were based on preliminary observations and species-time curves. Individuals observed were identified to species (Walker and Corbet 1978, Dunkle 2000) and their abundance recorded. Individuals that could not be identified to species were identified to the lowest level possible (typically genus). In 2003 the sex of individuals was also recorded. All observations were conducted on sunny days with low wind between 12 and 5 pm (US eastern daylight savings time).

To measure recruitment into tanks, all tanks were sampled for larvae three times in 2002 and 2003 (Table 1). One tank (half of one pair) was not sampled in April/May 2003 because winter mortality was substantial and no insects were detected in extensive dipnetting of this tank. All other sample periods involved fully sampling all tanks. To sample tanks, a solid divider was used to split individual tanks in half and form a seal with the edges to prevent movement of 
invertebrates between the two halves. A dipnet was used to collect all invertebrates and leaf litter from one half of the tank. Dipnetting continued until all leaf litter had been collected and several dips (a minimum of 8) were made without collecting additional invertebrates. Leaf litter and invertebrates were placed in a large plastic bin and mixed with water from the tank. Leaves were rinsed and thoroughly searched for invertebrates, which were collected and placed in $70 \%$ ethanol for later identification. After searching leaves, the remaining water was filtered through successively smaller sieves. Invertebrates caught in the filters were collected and preserved in $70 \%$ ethanol. All equipment was thoroughly rinsed with wellwater before moving between tanks to prevent cross contamination. Dipnet sampling was also conducted in July 2003 to look for Sympetrum species which overwinter in the egg stage and could emerge prior to the August sampling in that year. The presence or absence of these species was noted for each tank. Preserved dragonfly larvae were identified to species (Walker and Corbet 1978, Bright and O'Brien 1999) and counted. Individuals that were too small to be identified to species were identified to genus or family.

\section{Observations at lakes and fields}

To assess patterns of species' movements through terrestrial habitats in the absence of artificial ponds and to ensure cattle tanks did not act as attractors to some species, observations were made of adult dragonflies at lakes and in terrestrial habitats without cattle tanks. Observations were conducted at four lakes and in two sets of fields, one close $(<100 \mathrm{~m})$, and one far (ca $1 \mathrm{~km}$ ) from each lake, for a total of eight fields. Species counts of dragonflies were made at each site by slowly walking a $50 \mathrm{~m}$ transect through (fields) or along the edge of (lakes) the habitat for 10 min while scanning with the naked eye and with binoculars. There were three observation periods in 2003 and two in 2004, spread throughout the flight season. Because of a long period of bad weather, one lake and its associated fields were observed only once in 2003. All observations were made on sunny days with low wind between 12 and $5 \mathrm{pm}$ (US eastern daylight savings time).

\section{Analysis of isolation and community structure}

Analyses used the cumulative community observed or collected at pairs of tanks after two years (20022003). Adults (dispersers) and larvae (colonists) were analyzed separately. Individuals identified only to genus were excluded from analyses unless they were the sole representative of the genus. In this circumstance these individuals were used to calculate richness and in comparisons of community composition.
To assess the effects of dispersal and recruitment limitation on richness at artificial ponds, I examined the relationship between the isolation of artificial ponds and the richness at these ponds. Two measures of isolation were used to examine this effect. Both measures examine the effects of distance from permanent waterbodies. Artificial ponds themselves were not significant sources for dragonflies because over-wintering mortality was nearly absolute and larval dragonflies rarely survive the winter in cattle tanks in this climate. The simplest measure of isolation used was nearest neighbor distance - how far a pair of tanks was from a permanent water-body. The second measure of isolation incorporated the potential contribution of all permanent waterbodies in a $3 \times 3 \mathrm{~km}$ region encompassing the ESGR and an area to the south of the ESGR. The western and northern edges of the ESGR are bounded by farms that contain no permanent lakes or ponds. There were eight permanent water-bodies in this region, including a set of human-made experimental ponds in the northeast corner of the ESGR that were treated as a single unit by summing the total area they encompass. This measure, connectivity $\left(\mathrm{S}_{\mathrm{i}}\right)$, is considered a more comprehensive measure of isolation than nearest neighbor distance (Moilanen and Nieminen 2002). Connectivity incorporates both distance to source habitats and habitat area as a proxy for population size. In this system using area as a means of weighting sources also incorporates the strong positive relationship between habitat area and species richness of the dragonfly community (McCauley 2005) into the connectivity measure. Connectivity is an inverse measure of isolation and $\mathrm{S}_{\mathrm{i}}$ increases as replicates are more connected to potential sources. Hanski's index of connectivity (1999) was used:

$$
S_{i}=\sum_{j \neq i} \exp \left(-\alpha d_{i j}\right) A_{j}
$$

where, $\alpha$ is a measure of the effect of distance on migration ( $1 / \alpha$ is the mean migration distance), $d_{i j}$ is the mean distance (edge to edge) between a source pond and the tanks in a pair, and $\mathrm{A}_{\mathrm{j}}$ is the area of the source pond. The parameter $\alpha$ was estimated by determining the mean dispersal distance for each species in this study based on how far individuals were observed from known sources and then using the mean of this distance in kilometers across species for both years to calculate $\alpha$. These data estimated an $\alpha$-value of 2.7. Specific $\alpha$-values are not expected to affect the rankings of connectivity within a data set (Hanski 1999). However, to explore the sensitivity of this measure to estimations of $\alpha$, connectivity measures were also calculated using $\alpha$-values of 1 and 2 . All three connectivity values ( $\alpha=1,2$, and 2.7) were then used in analyses of the relationship between connectivity and richness. Values $>2.7$ were thought to represent unrealistically short dispersal distances. Linear regression was used to assess the effects of isolation on species 
richness at artificial ponds. Nearest neighbor distance and connectivity $\left(\mathrm{S}_{\mathrm{i}}\right)$ were used as explanatory variables while richness was used as the response variable. Because of the relatively low sample size in this study, I used two methods (Cook's distance and leverage values) to evaluate the overall influence of each pair of tanks on all regression models relating richness to both measures of isolation (distance from source and connectivity). Analyses were conducted in SPSS 11.5.

To test for spatial effects on community composition, Mantel tests were used to examine the correlation between the community dissimilarity (1- Jaccard's coefficient of similarity) and matrix of distances between tank pairs. Separate analyses for dispersers (adults) and colonists (larvae) were conducted. The calculated correlation between community dissimilarity and distance were compared to the correlations calculated for 10000 randomized dissimilarity-distance matrices. Mantel analyses and randomizations were conducted using PopTools (Hood 2005) in Microsoft Excel ${ }^{\mathrm{TM}}$.

I used G-power (Faul and Erdfelder 1992) to assess the power of all regression and correlation analyses to detect significant relationships between richness and measures of isolation (distance to source or connectivity) and between community dissimilarity and inter-tank distance.

To assess whether the presence of artificial ponds in fields would attract or repel species present in the regional species pool, Jaccard's coefficient of similarity was used to compare the community observed at four natural lakes and eight fields to the pool of species observed as dispersers at all artificial ponds. To assess the degree of similarity in species' dispersal patterns in these two data sets, Jaccard's was used to compare the species pool observed in fields without tanks to the species observed at artificial ponds located in fields with experimental tanks.

\section{Results}

There were high levels of both dispersal to and colonization of the cattle tanks by dragonflies. A total of 499 individual adult dragonflies, representing 21 species, were observed at cattle tanks (Appendix A) and 10405 dragonfly larvae in 14 species were collected from these tanks (Appendix B). A number of other macro-invertebrate colonists including a diverse assemblage of insects as well as gastropods were also collected from cattle tanks, suggesting that these tanks functioned effectively as small ponds.

The richness of adult dispersers observed at artificial ponds decreased with increasing isolation. There was a negative relationship between distance to the nearest source habitat and the cumulative richness of adults observed at tanks $\left(\mathrm{F}_{1,6}=6.0, \quad \mathrm{p}=0.05, \quad \mathrm{R}^{2}=0.50\right.$;
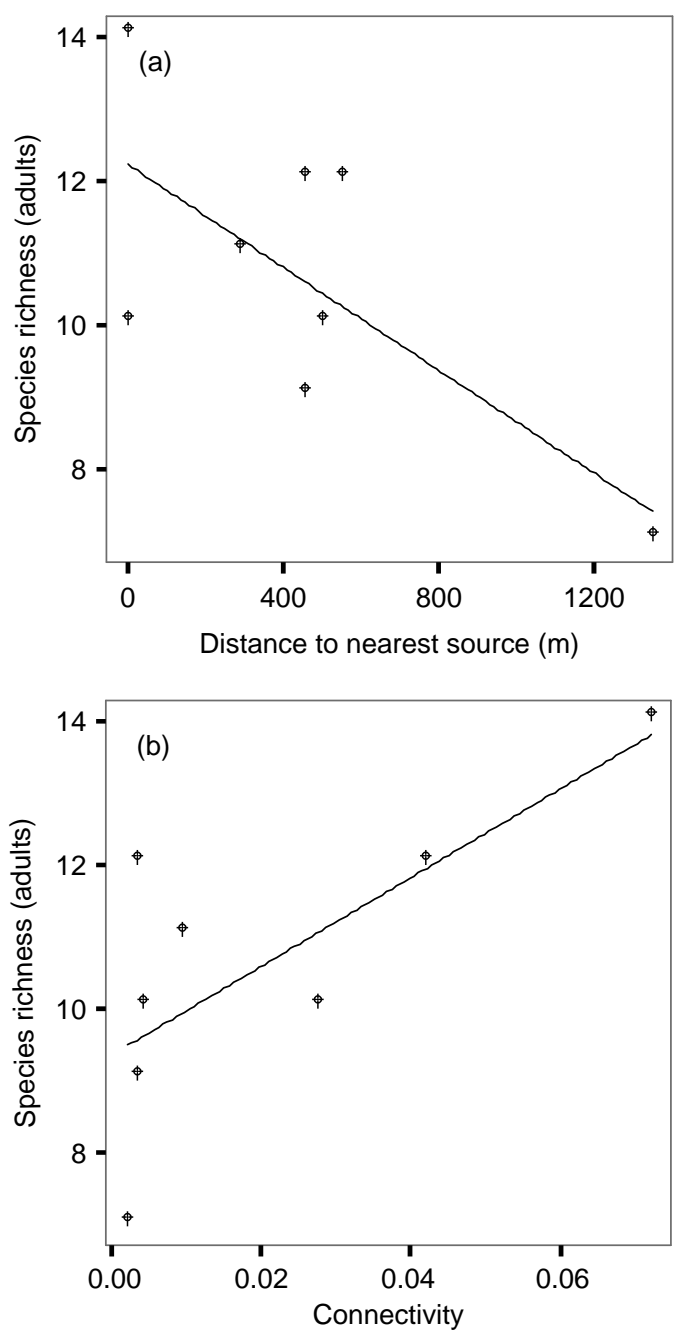

Fig. 2. Relationship between species richness of adult dispersers and tank isolation for (a) species richness relative to nearest source distance and (b) species richness relative to tank connectivity.

Fig. 2a). Connectivity was positively related to the cumulative richness of adult dispersers observed at tanks $\left(\alpha=2.7, F_{1,6}=7.02, p=0.04, R^{2}=0.54\right.$; Fig. $\left.2 b\right)$. There was a significant positive relationship between connectivity and adult disperser richness across all values of $\alpha$ tested (all $\mathrm{p}<0.04$ ).

A sex-bias was detected in the adults observed at tanks in 2003. Although it was not always possible to identify definitively the sex of dispersers at tanks (in many species immature males and females have the same color patterns and markings), mature males were the most common sex of adults observed at tanks. In 2003, 175 individuals definitively identified as males were observed at cattle tanks while 95 individuals were identified as females or immatures. Twenty individuals could not be placed in either category. If all individuals not identified as male are assumed to be female the sex ratio at tanks 
would be male biased (1.5:1). This assumption is, however, improbable and the sex ratio is likely to be even more male biased than 1.5:1.

Species richness of the larval dragonfly communities forming in artificial ponds also decreased with increasing isolation. Distance to the nearest permanent lake was negatively related to larval richness and explained $75 \%$ of the variation in richness among tanks $\left(\mathrm{F}_{1,6}=18.34\right.$, $\mathrm{p}=0.005, \mathrm{R}^{2}=0.75$; Fig. 3a). Connectivity was positively related to richness $\left(\alpha=2.7, \mathrm{~F}_{1,6}=13.89, \mathrm{p}=0.01\right.$, $\mathrm{R}^{2}=0.70$; Fig. 3b). A significant positive relationship between connectivity and larval richness was found across all values of $\alpha$ tested (all $\mathrm{p}<0.02$ ).

Based on published criteria, leverage statistics did not identify any tank pair as having undue influence in any of the regression models. All leverage values were
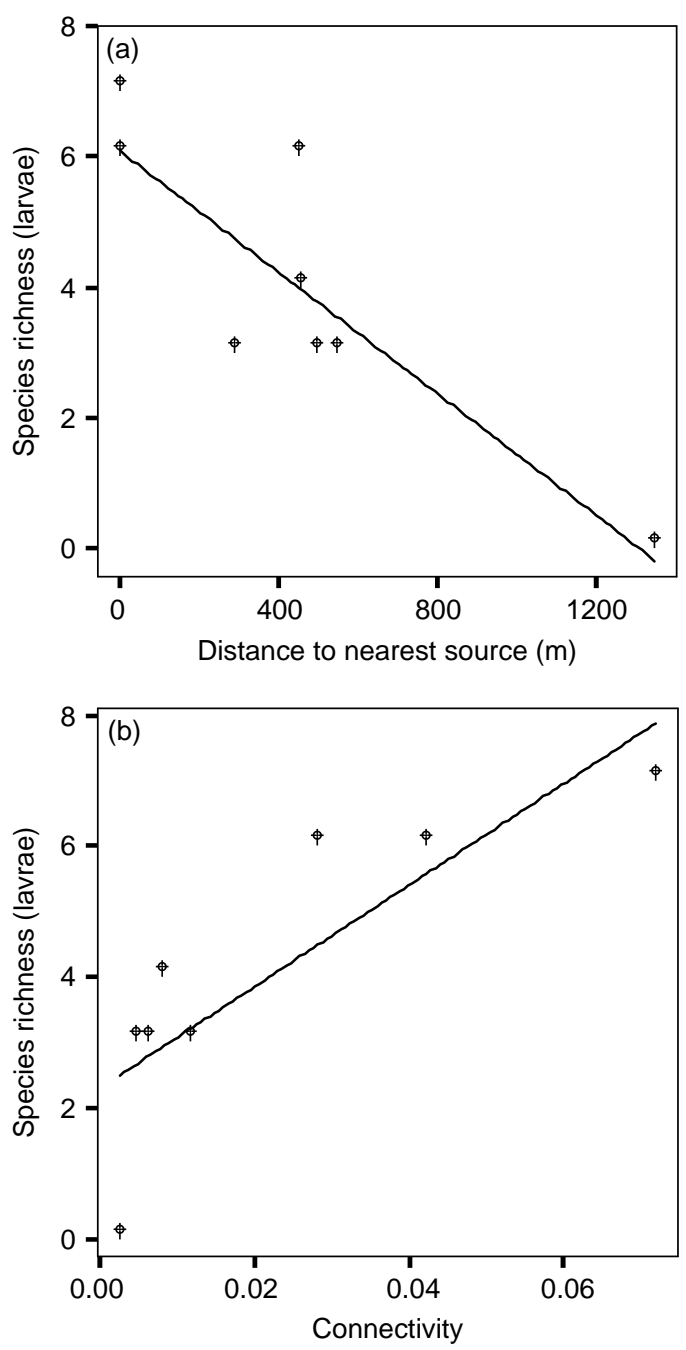

Fig. 3. Relationship between species richness of larval colonists and tank isolation for (a) cumulative species richness relative to nearest source distance and (b) cumulative species richness relative to tank connectivity.
$<0.75$, the cut-off recommended based on number of predictors and sample size of these analyses (Stevens 1992). Cook's distance values $>1$ may exert undue influence on the regression model (Cook and Weisberg 1982) and in the analysis of the relationship between connectivity and larval richness one tank pair (pair 1) had a Cook distance value $>1$. However, dropping this tank pair and reanalysing this relationship found little effect on the relationship (both regressions were significant and the $\mathrm{R}^{2}$ value changed from 0.70 to 0.69 ). No other tank pairs were identified as having undue influence based on Cook distance values. Based on Cohen's (1988) effect size criteria, power analyses in G-Power (Faul and Erdfelder 1992) for all regressions indicated that analyses had adequate power to detect significant relationships between measures of isolation and richness.

A Mantel test found no significant correlation between the composition of adults observed at artificial ponds and distance between these sites $(r=0.23$, $\mathrm{p}=0.12$ ). However, for larvae the Mantel test found that community dissimilarity and distance between artificial ponds were positively correlated $(\mathrm{r}=0.52$, $\mathrm{p}=0.02$ ). Power analyses indicated a medium level of power (power $=0.45$ ) to detect a significant relationship between larval community dissimilarity and inter-tank distance and a low level of power (power $=0.15$ ) to detect a significant relationship between these variables in adults (criteria based on Cohen 1988).

\section{Observations at lakes and fields}

The presence of cattle tanks in fields did not appear to affect the composition of dispersers in fields. The species observed at natural lakes and fields were similar to the adults observed in the experiment (Jaccard's coefficient of similarity $=0.95)$. With the exception of one species (Cordulia shurtleffi), all species observed at lakes and in fields without cattle tanks were also observed at cattle tanks and all species of adults observed at cattle tanks were observed at natural lakes and fields. The similarity between species observed in fields with and without cattle tanks was also relatively high (Jaccard's coefficient of similarity $=0.78$ ). There were two species observed in fields without cattle tanks that were not observed at cattle tanks and two species observed at experimental cattle tanks placed in fields but not in fields without cattle tanks. Fourteen species were observed in both sets of fields. This analysis suggests that while there was not complete overlap in the species observed in fields with and without cattle tanks, the presence of cattle tanks was not drawing in a wholly new set of species to these fields and that species observed as adults at cattle tanks in fields were largely those already present in these environments. 


\section{Discussion}

Results from this experiment suggest three conclusions. First, that dispersal and recruitment limitation act as filters on community structure in ponds. Second, the effects of isolation acted more strongly on the larvae recruiting into tanks than the adults observed dispersing to tanks, and further observations suggest that the size and sex-ratio of the dispersers arriving at a site may further limit the pool of species capable of recruiting into that site. Finally, distance between tanks and community dissimilarity of larvae in tanks were positively correlated. These results indicate a spatial component to the structure of communities forming in these artificial ponds. These results were part of a broader study and several aspects of the design should be refined in further work to assess these conclusions. In particular, because multiple water-bodies may be sources for the dispersers and colonists at artificial ponds, results based on distance to a single source should be interpreted cautiously. Connectivity is likely to provide a better measure of true levels of isolation in this landscape and in most others. However, both measures of isolation, connectivity (a measure which accounts for the contributions of multiple sources) and distance to the nearest source, indicate similar relationships between that isolation and richness. The similarity of these results indicate that the pattern is consistent but that further work may refine our understanding of the relative contributions of different water-bodies across a landscape. Nonetheless, the patterns observed in this study were striking, suggesting that spatial context can affect the structure of communities forming in ponds, and these results have implications for aquatic habitats that should continue to be evaluated in natural landscapes.

Isolation was negatively related to the number of species arriving at and recruiting into artificial ponds that were physically identical but differed in their placement across a landscape and their degree of isolation. This result was robust across multiple methods of measuring habitat isolation. Significant negative relationships between richness for both adults and larvae were found for all measures of isolation, nearest neighbor distance as well as connectivity calculated across a range of mean dispersal distances (using $\alpha$ values of 1,2, and 2.7). Together these data indicate that in this system dispersal and recruitment limitation act as filters on the communities forming at these newly available habitats. Fewer species reached tanks which were far from their source habitats than tanks which were close. The persistence of this effect on cumulative community composition after two years also indicates that dispersal and recruitment limitation may affect community structure over time periods relevant in the natural system. Many natural ponds in this region experience disturbance as a result of drying leading to local extinctions within the time period encompassed by this study (Skelly et al. 1999, Werner et al. pers. comm.). As these communities recover from disturbance, the number of species recolonizing is likely to be negatively impacted by their degree of isolation. This may have important consequences for both the composition of these communities and for the maintenance of a number of species in this system. Although the majority of species in this study over-winter in the larval stage and go locally extinct in ponds that dry, surveys of dragonfly larvae in 57 natural lakes and ponds over multiple years found that many of these species frequently utilize nonpermanent sites and comprise an average of $40 \%$ of the species in these ponds (McCauley et al. unpubl.). These non-permanent sites are highly dynamic and include sites with a wide range of drying regimes. Some of these ponds dry every year, other ponds between 2 and 5 times a decade, while still others dry on an ca $30 \mathrm{yr}$ cycle during extreme drought events (Werner et al. pers. comm.). Non-permanent sites operate as sink environments when they dry but may be important source habitats when they hold water for a full year. This study was conducted during drought conditions, making nonpermanent sites sinks during the period of this study, but long-term data indicate that the role of these ponds changes over time with ponds regularly shifting between the roles of source and sink and that non-permanent sites contribute to the maintenance of species in this system as ponds shift between source and sink conditions and species go locally extinct in both permanent and non-permanent sites (McCauley et al. unpubl.). This makes the role of dispersal limitation and the effects of isolation on richness in ponds a critical question for understanding broader patterns of species persistence and dynamics in this system. This study indicates that dispersal limitation and isolation do affect community composition in this system, although how long the effects of dispersal limitation continue to impact communities in these ponds is unknown. Nonetheless, the effects were of sufficient duration that they are likely to have an impact in many habitats although their relative effect may change temporally, being greater in dry or drought periods than in wetter time periods when disturbance by drying may be less frequent.

The relatively limited dispersal of many species in this study was surprising given that dragonflies can be powerful fliers and most species are likely to be capable of dispersing fairly long distances. Nonetheless, these results join a growing body of literature which suggests that few individuals achieve their maximum potential dispersal distances and that most individuals disperse distances considerable shorter than their observed maximum (Conrad et al. 1999, Purse et al. 2003) and some groups show high levels of philopatry (McPeek 1989, Angelibert and Giani 2003). Although low levels of dispersal are not universal in odonates (Michiels and 
Dhondt 1991), results from this study and other work suggest that for many odonate species dispersal limitation may be important on the time scales relevant to the ecology of the semi-permanent ponds. This dispersal limitation appears to be behaviorally based, as many species of dragonfly are known to be capable of long distance flight including migration (Corbet 1999). The evolution of behaviorally limited dispersal may result from direct dispersal costs or spatial variation in habitat quality, factors which may select for low dispersal rates (Levin et al. 1984, Holt 1985, Denno et al. 1989, Mathias et al. 2001) and distances (Murrell et al. 2002).

Results in odonates are paralleled in other groups of aquatic taxa where relatively low dispersal rates and distances have been observed for taxa apparently capable of crossing through the inter-habitat matrix and dispersing to new habitats (zooplankton: Jenkins and Buikema 1998, Cáceres and Soluk 2002, insects: Collier and Smith 1998, Griffith et al. 1998, Delettre and Morvan 2000, Milner et al. 2000, Wilcox 2001, Petersen et al. 2004, mixed patterns in Vieira et al. 2004, amphibians: Sjögren-Gulve 1994). Results from these studies suggest that the role of dispersal limitation in structuring communities subject to disturbance may be largely underestimated as an effect on community structure over habitat gradients. Additionally, the temporal scale of these effects may be far longer than has generally been anticipated. One study found what appeared to be behaviorally based differences in dispersal distances between mayfly (Ephemeroptera) species following glacial recession. These species differed 10 -fold in the distance they had dispersed over the course of $220 \mathrm{yr}$ despite apparently similar morphological flight capacities (Milner et al. 2000).

The effects of distance more strongly influenced the larval community collected from tanks than the richness of adult dispersers observed at tanks. This pattern is not unexpected considering the requirements for colonization of the tanks are more restrictive than for dispersal to tanks. For tanks to be colonized by larvae, either an already mated, gravid female or a male-female pair must arrive at the tank and choose to oviposit there. For adults to be recorded as present at a tank, only a single individual of either sex and in any state needed to arrive at the tank. Colonization of ponds or cattle tanks by dispersers arriving from distant sources may be constrained by the size and sex-ratio of the dispersal kernel arriving at these sites. Observations in 2003 found a male bias in the adults arriving at tanks, with the male: female ratio observed at tanks being at least 1.5:1 and likely much higher. The underlying mechanisms for why males were observed to disperse more frequently than females are unknown and it is possible that differences in male and female attraction to water or habitat selection behavior may have influenced this finding. Work in some odonates suggests greater dispersal rates by females which typically spend less time at ponds than males (Angelibert and Giani 2003). Nonetheless, if there is a male biased sex ratio in dispersers in this system this would exacerbate the effects of dispersal limitation on recruitment in isolated habitats and result in stronger effects of isolation than observations of dispersal alone would suggest. The sex ratio of dispersing dragonflies appears to be an important factor underlying the differences in the effects of isolation on recruitment versus dispersal in this experiment.

The spatial arrangement of tanks also affected the compositional similarity of the larval communities forming in artificial ponds. Low power in the analysis limited my ability to conclude no relationship between community dissimilarity and inter-tank distance for adults, and it is possible that with more pairs of tanks in the landscape a significant relationship would be detected. However, these results generally support the relationships seen in other analyses, that larval colonization is more restricted by distance than adult dispersal. There was a clear relationship in larval communities and more distant tanks shared fewer colonist species. Tanks could vary widely in their composition across a range of distances, presumably as a result of factors unmeasured in this experiment, but tanks which are far apart never share many species. Tanks in this experiment were placed both adjacent to and at a range of distances from source habitats with different species pools. The effects of intertank distance on the similarity of the colonist communities forming in tanks indicates that community structure of habitats can be affected not only by their degree of isolation but also by their proximity to different source pools. This provides further evidence that there is not uniform dispersal and recruitment at this spatial scale. Tanks located in different parts of the landscape received different recruits, even though the artificial ponds were physically identical and there is a spatial component to the composition of these communities. These results suggest that landscape structure and the placement of sites with respect to more permanent source habitats influences two critical aspects of community structure, richness and species composition, over time scales likely to be relevant in many semi-permanent ponds.

The relative importance of local versus regional factors in limiting the composition of communities depends on the balance between local extinction and dispersal rates (Cornell and Karlson 1997, Loreau and Mouquet 1999, Shurin 2000, Kneitel and Miller 2003). Many communities are organized along habitat gradients that include transitions in the permanence of the habitat and consequent local extinction rates (aquatic systems: Schneider and Frost 1996, Wellborn et al. 1996, terrestrial systems: Connell 1978, Tilman 1997, Collins 2000). The impact of dispersal limitation on community structure is likely to vary along this gradient but may be 
critical in non-permanent habitats in which disturbance and local extinction potentially keep these communities from reaching saturation and species may be absent from otherwise suitable sites because they have not dispersed and recruited into sites in the inter-disturbance interval (Pulliam 2000, Hanski 2001). Despite the importance of these habitat gradients in diverse systems, there has been relatively little work examining the effects of dispersal limitation on species distributions across habitat gradients (Tilman 1994, Gilbert and Lechowicz 2004, Ozinga et al. 2005). Results from this work suggest habitat isolation may act as a filter on recruitment, over a time scale that reflects the disturbance frequencies of many of the ponds in the region where this study was conducted (Skelly et al. 1999, Werner et al. pers. comm.). Local factors and larval performance also undoubtedly contribute to the structuring of aquatic communities, and the role of drying tolerance is critical for species occupying the most temporary end of the permanence gradient. However, the majority of species in this system, including the majority of species found in semi-permanent ponds which dry periodically but not every year, can not tolerant habitat drying and experience local extinctions when drying occurs (McCauley 2005). In this experiment, of the fourteen species that colonized artificial ponds only one (Sympetrum vicinum) has a diapausing egg stage which can survive habitat drying and one has a limited ability to survive drying in the larval stage (Libellula pulchella, S. A. Wissinger pers. comm., Werner et al. pers. comm.). The remaining twelve species collected from this experiment can not survive habitat drying. Consequently, for these species and for most species in the surrounding natural lakes and ponds, their dispersal and recruitment behavior rather than drying tolerance is the critical factor determining their presence in semi-permanent sites. Results from this study highlight the potential importance of dispersal limitation of adults and larval recruitment into sites in structuring aquatic communities across habitat gradients.

In aquatic communities, or other systems characterized by environmental gradients related to disturbance frequency, species richness in sites may be decreased by dispersal and recruitment limitation and differences between species may be important in shaping species distributions along this gradient. Results from this study suggest that the role of dispersal limitation may be underestimated in systems where the species are potentially good dispersers but are behaviorally limited in this process. To develop a more complete picture of the processes structuring communities more evidence relevant to the spatial and temporal scale of the habitat dynamics within communities needs to be collected. The implications for applied ecology are also significant. Habitat restoration efforts need to consider how the spatial arrangement of newly created sites is likely to be perceived by diverse groups in the systems being restored. This study suggests that global dispersal and recruitment is an unlikely assumption, even at spatial scales that would apparently be within the reach of the dispersers.

Acknowledgements - The research presented in this paper was submitted to the Dept of Ecology and Evolutionary Biology at the Univ. of Michigan as part of a dissertation in partial fulfillment of the requirements for the degree of Doctor of Philosophy. I thank the people who assisted with fieldwork in this experiment: E. Werner, J. Nystrom, C. Davis, S. Schneider, J. Richardson, G. Horst, V. Pherigo, L. DeMattia, M. Nystrom, and K. Judd. E. Werner, D. Goldberg, B. Hazlett, and E. Silverman all provided helpful advice in developing this project and insightful comments on an earlier version of this manuscript. I am grateful to E. Werner, L. Schiesari, S. Schneider, M. Zimmerman, E. Svensson, and D. Srivastava for insightful comments on this manuscript. The Museum of Zoology and R. Nussbaum provided access to the ESGR and the Fresh Air Camp and J. Bolgos provided logistical support at both sites. This research was funded by NSF grants DEB9727014 to E. Werner, D. Skelly, R. Relyea, and K. Yurewicz and DEB-0089809 to E. Werner and S. Peacor and by grants from the Univ. of Michigan including a Sokol grant to E. Werner and S. McCauley and grants from the Dept of Ecology and Evolutionary Biology and the Museum of Zoology to S. McCauley. A Univ. of Michigan Rackham Predoctoral Fellowship provided support during the initial writing of this manuscript.

\section{References}

Angelibert, S. and Giani, N. 2003. Dispersal characteristics of three odonate species in patchy habitat. - Ecography 26 : $13-20$.

Bernath, B. et al. 2002. How can dragonflies discern bright and dark waters from a distance? The degree of polarisation of reflected light as a possible cue for dragonfly habitat selection. - Freshwater Biol. 47: 1707-1719.

Boehms, C. N. 1971. The influence of temperature upon embryonic diapause and seasonal regulation in Sympetrum vicinum (Hagan) (Odonata: Libellulinae). - Ph.D. thesis, Univ. of North Carolina at Chapel Hill, Chapel Hill, NC.

Bright, E. and O’Brien, M. F. 1999. Michigan Odonate Survey: Odonata larvae of Michigan. $-<$ http://insects.ummz.lsa. umich.edu/MICHODO/test/HOME.HTM > .

Cáceres, C. E. and Soluk, D. A. 2002. Blowing in the wind: a field test of overland dispersal and colonization by aquatic invertebrates. - Oecologia 131: 402-408.

Cohen, J. 1988. Statistical power analysis for the behavioral sciences, 2nd ed. - Academic Press.

Collier, K. J. and Smith, B. J. 1998. Dispersal of adult caddisflies (Trichoptera) into forests alongside three New Zealand streams. - Hydrobiologia 361: 53-65.

Collins, S. L. 2000. Disturbance frequency and community stability in native Tallgrass Prairie. - Am. Nat. 155: $311-$ 325.

Connell, J. H. 1978. Diversity in tropical rain forests and coral reefs. - Science 199: 1302-1310.

Conrad, K. F. et al. 1999. Dispersal characteristics of seven odonate species in an agricultural landscape. - Ecography 22: 524-531.

Cook, R. D. and Weisber, S. 1982. Residuals and influence in regression. - Chapman and Hall.

Corbet, P. S. 1999. Dragonflies: behavior and ecology of Odonata. - Comstock Publ. Associates, Cornell Univ. Press. 
Cordero Rivera, A. et al. 2005. Parthenogenetic Ishnua hastata (Say), widespread in the Azores (Zygoptera: Coenagrionidae). - Odonatologica 34: 1-9.

Cornell, H. V. and Lawton, J. H. 1992. Species interactions, local and regional processes, and limits to the richness of ecological communities: a theoretical perspective. - J. Anim. Ecol. 61: 1-12.

Cornell, H. V. and Karlson, R. H. 1997. Local and regional processes as controls of species richness. - In: Tilman, D. and Kareiva, P. (eds), Spatial ecology. Princeton Univ. Press, pp. $250-268$.

Cottenie, K. and DeMeester, L. 2003. Connectivity and cladoceran species richness in a metacommunity of shallow lakes. - Freshwater Biol. 48: 823-832.

Cottenie, K. and DeMeester, L. 2004. Metacommunity structure: synergy of biotic interactions as selective agents and dispersal as fuel. - Ecology 85: 114-119.

Cottenie, K. et al. 2003. Zooplankton metacommunity structure: regional vs. local processes in highly interconnected ponds. - Ecology 84: 991-1000.

Delettre, Y. R. and Morvan, N. 2000. Dispersal of adult aquatic Chironomidae (Diptera) in agricultural landscapes. - Freshwater Biol. 44: 399-411.

Denno, R. F. et al. 1989. Reproductive cost of flight capability: a comparison of life history traits in wing dimorphic planthoppers. - Ecol. Entomol. 14: 31-44.

Dunkle, S. W. 2000. Dragonflies through binoculars: a field guide to dragonflies of North America. - Oxford Univ. Press.

Faul, F. and Erdfelder, E. 1992. GPOWER: a priori, post-hoc, and compromise power analyses for MS-DOS [Computer program]. - Dept of Psychology, Bonn Univ., Bonn FRG.

Gilbert, B. and Lechowitz, M. J. 2004. Neutrality, niches, and dispersal in a temperate forest understory. - Proc. Nat. Acad. Sci. USA 101: 7651-7656.

Griffith, M. B. et al. 1998. Lateral dispersal of adult aquatic insects (Plecoptera, Trichoptera) following emergence from headwater streams in forested Appalachian catchments. - Ann. Entomol. Soc. Am. 91: 195-201.

Hanski, I. 1999. Metapopulation ecology. - Oxford Univ. Press.

Hanski, I. 2001. Population dynamic consequences of dispersal in local populations and in metapopulations. - In: Clobert, J. et al. (eds), Dispersal. Oxford Univ. Press, pp. 283-298.

Holt, R. D. 1985. Population dynamics in two-patch environments: some anomalous consequence of an optimal habitat distribution. - Theor. Popul. Biol. 28: 181-208

Hood, G. M. 2005. PopTools ver. 2.6.9. - < http://www.cse. csiro.au/poptools $>$.

Jenkins, D. G. and Buikema, A. L. 1998. Do similar communities develop in similar sites? A test with zooplankton structure and function. - Ecol. Monogr. 68: 421-443.

Kneitel, J. M. and Miller, T. E. 2003. Dispersal rates affect species composition in metacommunities of Sarracenia purpurea inquilines. - Am. Nat. 162: 165-171.

Koenig, W. D. and Albano, S. S. 1987. Lifetime reproductive success, selection, and the opportunity for selection in the white-tailed skimmer Plathemis lydia (Odonata: Libellulidae). - Evolution 41: 22-36

Leibold, M. A. et al. 2004. The metacommunity concept: a framework for multi-scale community ecology. - Ecol. Lett. 7: $601-613$.

Levin, S. A. et al. 1984. Dispersal strategies in patchy environments. - Theor. Popul. Biol. 26: 165-191.

Loreau, M. and Mouquet, N. 1999. Immigration and the maintenance of local species diversity. - Am. Nat. 154: 427-440.

MacArthur, R. H. and Wilson, E. O. 1967. The theory of island biogeography. - Monographs in Population Biology, Princeton Univ. Press.
Mathias, A. et al. 2001. Divergent evolution of dispersal in a heterogeneous landscape. - Evolution 55: 246-259.

McCauley, S. J. 2005. Species distributions in anisopteran odonates: effects of local and regional processes. - Ph.D. thesis, Univ. of Michigan, Ann Arbor, MI.

McPeek, M. A. 1989. Differential dispersal tendencies among Enallagma damselflies (Odonata: Coenagrionidae) inhabiting different habitats. - Oikos 56: 187-195.

Michiels, N. K. and Dhondt, A. A. 1991. Characteristics of dispersal in sexually mature dragonflies. - Ecol. Entomol. 16: $449-459$.

Milner, A. M. et al. 2000. Colonization and development of stream communities across a 200-year gradient in Glacier Bay National Park, Alaska, U.S.A. - Can. J. Fish. Aquat. Sci. 57: 2319-2335.

Moilanen, A. and Nieminen, M. 2002. Simple connectivity measures in spatial ecology. - Ecology 83: 1131-1145.

Murrell, D. J. et al. 2002. The evolution of dispersal distance in spatially-structured populations. - Oikos 97: 229-236.

Ozinga, W. A. et al. 2005. Predictability of plant species composition from environmental conditions is constrained by dispersal limitation. - Oikos 108: 555-561.

Petersen, I. et al. 2004. Dispersal of adult aquatic insects in catchments of differing land use. - J. Appl. Ecol. 41: 934-950

Poff, N. L. 1997. Landscape filters and species traits: towards a mechanistic understanding and prediction in stream ecology. - J. North Am. Benthol. Soc. 16: 391-409.

Pulliam, H. R. 2000. On the relationship between niche and distribution. - Ecol. Lett. 3: 349-361.

Purse, B. V. et al. 2003. Dispersal characteristics and management of a rare damselfly. - J. Appl. Ecol. 40: 716-728.

Ricklefs, R. E. 1987. Community diversity: relative roles of local and regional processes. - Science 235: 167-171.

Schneider, D. and Frost, T. 1996. Habitat duration and community structure in temporary ponds. - J. North Am. Benthol. Soc. 15: 64-86.

Shurin, J. B. 2000. Dispersal limitation, invasion resistance, and the structure of pond zooplankton communities. - Ecology 81: $3074-3086$.

Sjögren-Gulve, P. 1994. Distribution and extinction patterns within a northern metapopulation of the pool frog, Rana lessonae. - Ecology 75: 1357-1367.

Skelly, D. et al. 1999. Long-term distributional dynamics of a Michigan amphibian assemblage. - Ecology 80: 2326-2337.

Srivastava, D. S. 1999. Using local-regional richness plots to test for species saturation: pitfalls and potentials. - J. Anim. Ecol. 68: 1-16.

Stevens, J. P. 1992. Applied multivariate statistics for the social sciences, 2nd ed. - Erlbaum.

Tilman, D. 1994. Competition and biodiversity in spatially structured habitats. - Ecology 75: 2-16.

Tilman, D. 1997. Community invasibility, recruitment limitation, and grassland biodiversity. - Ecology 78: 81-92.

Urban, M. C. 2004. Disturbance heterogeneity determines freshwater metacommunity structure. - Ecology 85: $2971-$ 2978.

Vieira, N. K. M. et al. 2004. Resistance and resilience of stream insect communities to repeated hydrologic disturbances after a wildfire. - Freshwater Biol. 49: 1243-1259.

Walker, E. M. and Corbet, P. S. 1978. The Odonata of Canada and Alaska. - Univ. of Toronto Press.

Wellborn, G. et al. 1996. Mechanisms creating community structure across a freshwater habitat gradient. - Annu. Rev. Ecol. Syst. 27: $337-363$.

Werner, E. E. and Glennemeier, K. 1999. Influence of forest canopy cover on the breeding pond distributions of several amphibian species. - Copeia 1999: 1-12.

Wilcox, C. 2001. Habitat size and isolation affect colonization of seasonal wetlands by predatory aquatic insects. - Israel $\mathbf{J}$. Zool. 47: 459-475. 